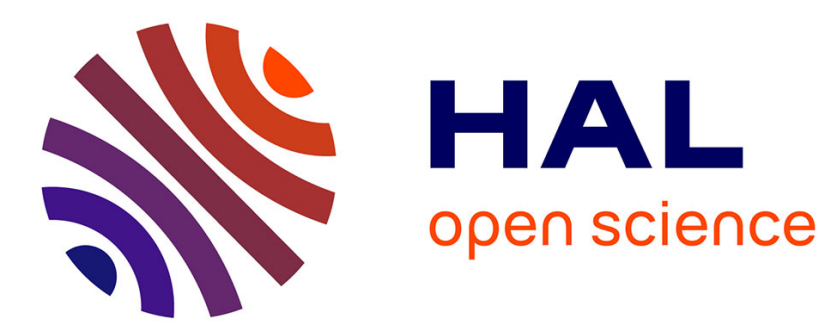

\title{
The effects of two internal rotations in the microwave spectrum of ethyl methyl ketone
}

Ha Vinh Lam Nguyen, Vinh Van, Wolfgang Stahl, Isabelle Kleiner

\section{To cite this version:}

Ha Vinh Lam Nguyen, Vinh Van, Wolfgang Stahl, Isabelle Kleiner. The effects of two internal rotations in the microwave spectrum of ethyl methyl ketone. Journal of Chemical Physics, 2014, 140 (21), pp.214303. 10.1063/1.4878412 . hal-03183160

\section{HAL Id: hal-03183160 https://hal.science/hal-03183160}

Submitted on 27 Mar 2021

HAL is a multi-disciplinary open access archive for the deposit and dissemination of scientific research documents, whether they are published or not. The documents may come from teaching and research institutions in France or abroad, or from public or private research centers.
L'archive ouverte pluridisciplinaire $\mathbf{H A L}$, est destinée au dépôt et à la diffusion de documents scientifiques de niveau recherche, publiés ou non, émanant des établissements d'enseignement et de recherche français ou étrangers, des laboratoires publics ou privés. 


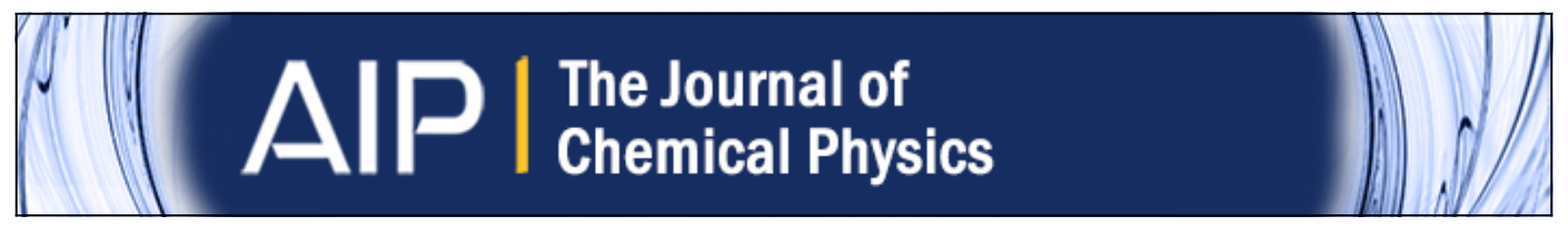

The effects of two internal rotations in the microwave spectrum of ethyl methyl ketone Ha Vinh Lam Nguyen, Vinh Van, Wolfgang Stahl, and Isabelle Kleiner

Citation: The Journal of Chemical Physics 140, 214303 (2014); doi: 10.1063/1.4878412

View online: http://dx.doi.org/10.1063/1.4878412

View Table of Contents: http://scitation.aip.org/content/aip/journal/jcp/140/21 ?ver=pdfcov

Published by the AIP Publishing

Articles you may be interested in

Rotational spectrum of tryptophan

J. Chem. Phys. 140, 204308 (2014); 10.1063/1.4876001

The effects of nitrogen inversion tunneling, methyl internal rotation, and $14 \mathrm{~N}$ quadrupole coupling observed in the rotational spectrum of diethyl amine

J. Chem. Phys. 135, 024310 (2011); 10.1063/1.3607992

Fourier transform microwave spectrum of CO-dimethyl ether

J. Chem. Phys. 127, 194302 (2007); 10.1063/1.2785185

Microwave and ab initio studies of the internal rotation of ethylene in the Ar-ethylene and Ne-ethylene van der Waals complexes

J. Chem. Phys. 119, 8449 (2003); 10.1063/1.1609974

Pure rotational spectrum and model calculations of indole-water

J. Chem. Phys. 119, 880 (2003); 10.1063/1.1578996

\section{AlP Re-register for Table of Content Alerts}




\title{
The effects of two internal rotations in the microwave spectrum of ethyl methyl ketone
}

\author{
Ha Vinh Lam Nguyen, ${ }^{1,2, a)}$ Vinh Van, ${ }^{1}$ Wolfgang Stahl, ${ }^{1}$ and Isabelle Kleiner ${ }^{2}$ \\ ${ }^{1}$ Institute of Physical Chemistry, RWTH Aachen University, Landoltweg 2, D-52074 Aachen, Germany \\ ${ }^{2}$ Laboratoire Interuniversitaire des Systèmes Atmosphériques (LISA), UMR 7583 (CNRS/Univ. Paris Est and \\ Paris Diderot), Université de Paris Est, 61 avenue du Général de Gaulle, F-94010 Créteil cedex, France
}

(Received 28 January 2014; accepted 5 May 2014; published online 2 June 2014)

\begin{abstract}
The rotational spectra of ethyl methyl ketone, $\mathrm{CH}_{3} \mathrm{CH}_{2} \mathrm{COCH}_{3}$, were measured in the microwave region from 2 to $40 \mathrm{GHz}$ using two molecular beam Fourier transform microwave spectrometers. Splittings due to internal rotations of both, the acetyl methyl group $-\mathrm{COCH}_{3}$ and the ethyl methyl group $\mathbf{C H}_{3} \mathrm{CH}_{2} \mathrm{CO}-$, could be completely resolved. All measured transitions were fitted using two different codes, XIAM and BELGI-Cs-2Tops. Molecular parameters like the rotational constants and the centrifugal distortion constants were determined with very high accuracy. The barrier to internal rotation of the acetyl methyl group was fitted to $181.502(98) \mathrm{cm}^{-1}$, much lower than the value of 763.87(65) $\mathrm{cm}^{-1}$ found for the ethyl methyl group. The splittings in the spectrum due to internal rotation of the acetyl methyl group are accordingly much larger, up to $1.2 \mathrm{GHz}$, whereas for the ethyl methyl group only splittings from a few hundreds of $\mathrm{kHz}$ up to $4 \mathrm{MHz}$ were observed. ( ) 2014 AIP Publishing LLC. [http://dx.doi.org/10.1063/1.4878412]
\end{abstract}

\section{INTRODUCTION}

Ethyl methyl ketone is one of the smallest aliphatic ketones which is widely used as a solvent in chemistry and industry. From a spectroscopic point of view, the methyl groups in ethyl methyl ketone undergo interesting dynamics, i.e., they internally rotate with different hindering barriers. The $\mathbf{C H}_{3} \mathrm{CH}_{2} \mathrm{CO}$ - methyl group will be called the ethyl methyl group and the $-\mathrm{COCH}_{3}$ methyl group the acetyl methyl group throughout this text. Ethyl methyl ketone has already been investigated very early in 1969 by Pierce et al. ${ }^{1}$ There, only rotational transitions in the vibrational ground state and only the internal rotation of the acetyl methyl group were reported. Twenty years later, Pozdeev et al. ${ }^{2}$ determined the barriers to internal rotation of both methyl groups, also obtained from measurements in the microwave region. For the acetyl methyl group, splittings in the torsional ground state could be resolved, yielding a barrier of $181.17(35) \mathrm{cm}^{-1}$. The higher barrier of the ethyl methyl group was reported to be $795(10) \mathrm{cm}^{-1}$ and could only be determined from very few resolvable splittings of some transitions in the ground state with high $J$ and high $K$ quantum numbers. ${ }^{2}$ Recently, new data of ethyl methyl ketone were recorded in the microwave and millimeter-wave regions from $8 \mathrm{GHz}$ to $1 \mathrm{THz}$. Quite a number of different program codes for fitting molecules with internal rotations were used to fit this data set. ${ }^{3}$ However, also in that work only the internal rotation of the lower-barrier acetyl methyl group was studied. This is clearly due to the fact that the splittings of the high-barrier ethyl methyl group were too small to be resolved in the spectra.

Using two molecular beam Fourier transform microwave (MB-FTMW) spectrometers in Aachen, many molecules which contain one or several ethyl groups were investigated. ${ }^{4}$

\footnotetext{
a) Author to whom correspondence should be addressed. Electronic mail: lam.nguyen@lisa.u-pec.fr. Telephone: +33 145882875.
}

In some cases like methyl propionate,${ }^{5}$ ethyl acetate,${ }^{6}$ diethyl ketone, ${ }^{7}$ and diethyl amine, ${ }^{8}$ splittings due to internal rotation of the ethyl methyl group could be resolved with the resolution of approximately $2 \mathrm{kHz}$ of the spectrometers. Therefore, we expected that those splittings in ethyl methyl ketone can also be resolved and this molecule should be treated as a two-top molecule. Quantum chemical calculations were carried out to get the necessary starting values.

In the past methyl propionate, $\mathrm{CH}_{3} \mathrm{CH}_{2} \mathrm{COOCH}_{3},{ }^{5}$ was measured and fitted with the programs XIAM ${ }^{9}$ and BELGICs-2Tops. ${ }^{10}$ We found an intermediate barrier to internal rotation of the methoxy methyl group $-\mathrm{OCH}_{3}$ of about $429 \mathrm{~cm}^{-1}$ and a high barrier of $820 \mathrm{~cm}^{-1}$ for the ethyl methyl group. In diethyl ketone, two equivalent ethyl methyl rotors show a similar barrier of $771.93(27) \mathrm{cm}^{-1}$. The splittings from the ethyl methyl group were several hundreds of $\mathrm{kHz}$ in both cases and we expect splittings in the same order of magnitude in the microwave spectrum of ethyl methyl ketone.

The title compound is also expected to be a good test case for the BELGI-Cs-2Tops code. The first molecule fitted with this program was methyl acetate $\mathrm{CH}_{3} \mathrm{COOCH}_{3},{ }^{10}$ which has an acetyl methyl group with low barrier to internal rotation and a methoxy methyl group with an intermediate barrier. The above mentioned molecule, methyl propionate, has one high and one intermediate barrier. Then, a third molecule with three isomers, 3,4- (syn and anti), 2,5- (syn), and 3,5dimethylbenzaldehyde (DMBA), which explored various barrier heights, was also studied. ${ }^{11}$ In the present study, results from the BELGI-Cs-2Tops code will be compared with those obtained from the XIAM code.

\section{EXPERIMENTAL SETUP}

The microwave spectrum of ethyl methyl ketone was carried out using two MB-FTMW spectrometers operating in 
the frequency ranges from 2 to $26.5 \mathrm{GHz}$ and from 26.5 to $40 \mathrm{GHz}$, respectively. The setups have been described in details in Refs. 12 and 13 and will not be repeated here. Ethyl methyl ketone was obtained from Merck Schuchardt, Hohenbrunn, Germany. A mixture of $1 \%$ ethyl methyl ketone in helium at a stagnation pressure of $100 \mathrm{kPa}$ for the pulsed jet was used to record all spectra.

The spectral lines were directly measured in the high resolution mode of the spectrometers. The line widths depend on the respective transitions and vary from 20 to $25 \mathrm{kHz}$. All lines are very strong, however, many of them have additional, clearly resolved small splittings, which might correspond to spin-spin or spin-rotation coupling of the protons. A spectrum with additional splittings is shown in Fig. S-F1 in the supplementary material. ${ }^{14}$ Therefore, the estimated accuracy of the line position for isolated lines rises to $4 \mathrm{kHz}$.

\section{QUANTUM CHEMICAL CALCULATIONS}

Neither in the old spectroscopic investigations ${ }^{1,2}$ nor in the more recent work ${ }^{3}$ quantum chemical calculations were reported. However, such theoretical methods became a powerful support to microwave spectroscopy in predicting stable conformers and barrier heights. On the other hand, the experimental parameters obtained by microwave spectroscopy are needed to verify the values calculated by quantum chemistry.

By rotating the ethyl group around the $\mathrm{C}_{1}-\mathrm{C}_{7}$ bond (for atom numbers see Fig. 1) a potential curve of ethyl methyl ketone was calculated. The dihedral angle $\varphi_{1}=\angle\left(\mathrm{O}_{2}, \mathrm{C}_{1}, \mathrm{C}_{7}, \mathrm{C}_{8}\right)$ was varied in steps of $1^{\circ}$ while all other geometry parameters were optimized. At first, the calculations were performed at the MP2/6-311++G(d,p) level of theory using the Gaussian 09 package. ${ }^{15}$ This method and basis set was chosen, since it yielded reasonable rotational constants for other ketones such as methyl isobutyl ketone ${ }^{16}$ and methyl neopentyl ketone. ${ }^{17}$ It is also widely used in the microwave spectroscopic community. ${ }^{18-20}$

The potential curves obtained using the different methods MP2, B3LYP, HF, and the basis set $6-311++\mathrm{G}(\mathrm{d}, \mathrm{p})$ are shown in Fig. 2. Three pairs of energetic minima are found in these curves. The fully optimized structures and addi-

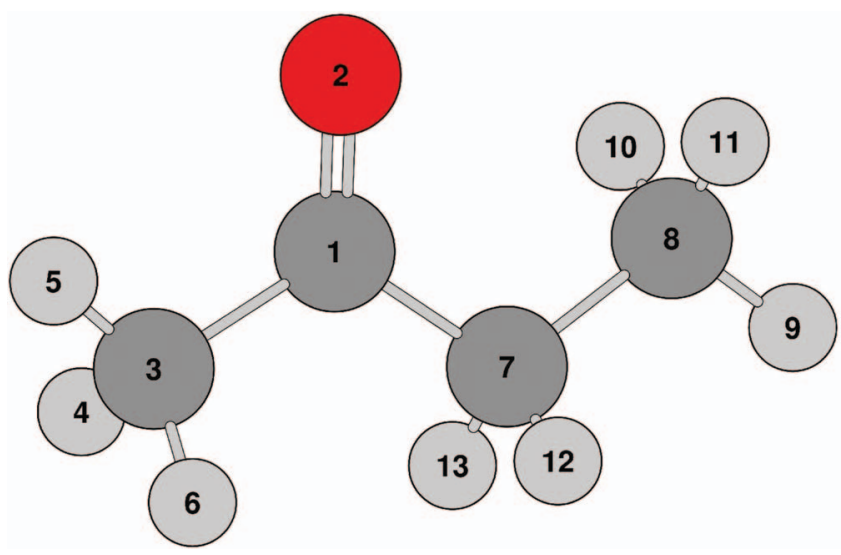

FIG. 1. The most energetic favorable conformer of ethyl methyl ketone calculated at the MP2/6-311++G(d,p) level of theory.

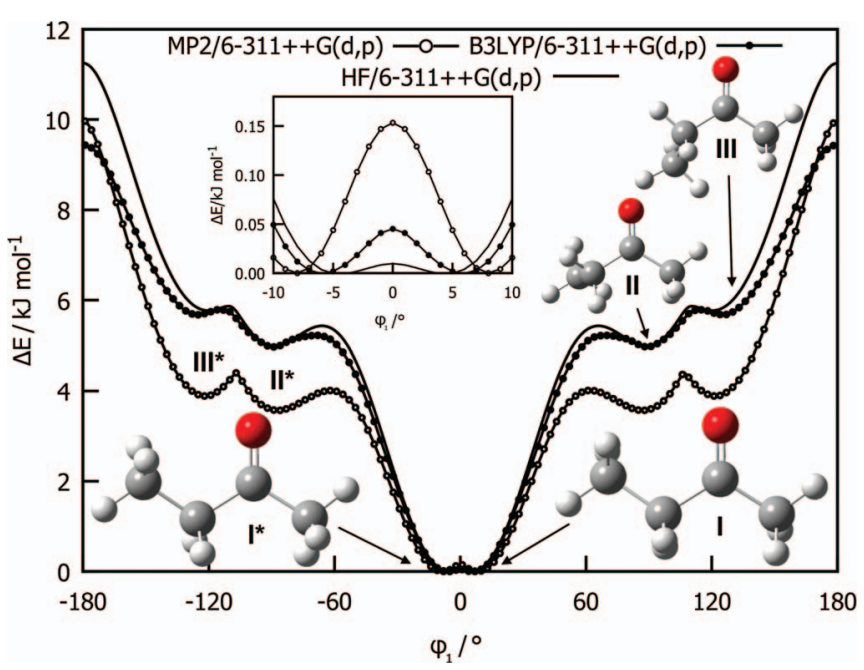

FIG. 2. The potential energy curve of ethyl methyl ketone obtained by rotating the ethyl group around the $\mathrm{C}_{1}-\mathrm{C}_{7}$ bond (varying the dihedral angle $\varphi_{1}$ $\left.=\angle\left(\mathrm{O}_{2}, \mathrm{C}_{1}, \mathrm{C}_{7}, \mathrm{C}_{8}\right)\right)$ in steps of $1^{\circ}$ calculated using different methods MP2, B3LYP, and HF with the 6-311++G(d,p) basis set. The relative energies with respect to the lowest energy conformer (see Fig. 1, total electronic energies $\mathrm{E}$ $=-231.851840$ Hartree, -232.543057 Hartree, and -231.061847 Hartree for the MP2, B3LYP, and HF method, respectively) are given. II* and III* are the enantiomers of conformer II and III. The double minimum located between $\varphi_{1}=-10^{\circ}$ and $+10^{\circ}$ is emphasized in an enlarged scale.

tional harmonic frequency calculations showed that all of them represent stable conformers rather than saddle points. However, two conformers (conformer II and III) are about $4 \mathrm{~kJ} / \mathrm{mol}$ higher in energy than the energetically lowest conformer (conformer I). Therefore, we expected that they cannot be observed in the microwave spectrum under our molecular beam conditions. Further optimizations and frequency calculations at different levels of theory such as correlation consistent basis sets including HF, DFT, MP2, and CCSD methods were performed for conformer I to check for geometry convergence. The combinations of the HF, B3LYP, and MP2 methods with the basis set 6-31G(d,p) and cc-pVDZ show an almost $\mathrm{C}_{\mathrm{s}}$ symmetry with the $\angle\left(\mathrm{i}_{1}, c\right)$ and $\angle\left(\mathrm{i}_{2}, c\right)$ angles very close to $90^{\circ}$ (see Table I). The optimized geometry at the MP2/6-311++G(d,p) level of theory shows a $C_{1}$ symmetry structure, where the ethyl group is tilted out of the molecular plane by an angle of $-8.40^{\circ}$. An overview of the quantum chemical calculations for all methods and basis sets for conformer I is given in Table I. Similar calculations for conformer II and III can be found in the supplementary material (Table S-1). ${ }^{14}$ The Cartesian coordinates of the nuclei in the principal axes of inertia for all conformers optimized at the MP2/6-311++G(d,p) level of theory are available in Table S-2, the Fourier coefficients of the three potential curves in Fig. 2 and in Table S-3a of the supplementary material. ${ }^{14}$

As mentioned above, the equilibrium geometry of the most stable conformer I depends strongly on the method and basis set. At the MP2/6-311++G(d,p) level of theory the optimized structure was lacking a symmetry plane and we found a $\mathrm{C}_{1}$ symmetry, whereas by "chemical intuition" a structure with a symmetry plane $\left(\mathrm{C}_{\mathrm{s}}\right)$ was expected. The ethyl group is tilted out of the acetyl plane by an angle of approximately $10^{\circ}$, represented by two minima which correspond to a pair 
TABLE I. The rotational constants $A, B$, and $C$ in GHz, the deviations (Dev.) between the experimental and calculated rotational constants in MHz, the angles between the internal rotor axis and the principal axes of inertia $\left(\mathrm{i}_{1}, a\right),\left(\mathrm{i}_{1}, b\right),\left(\mathrm{i}_{1}, c\right)$ of the acetyl methyl group and $\left(\mathrm{i}_{2}, a\right),\left(\mathrm{i}_{2}, b\right),\left(\mathrm{i}_{2}, c\right)$ of the ethyl methyl group, and the barrier to internal rotation $V_{3,1}$ of the acetyl methyl group and $V_{3,2}$ of the ethyl methyl group of conformer I calculated using various methods and basis sets.

\begin{tabular}{|c|c|c|c|c|c|c|c|c|c|c|c|c|c|c|}
\hline Method/basis set & $A$ & Dev. & $B$ & Dev. & $C$ & Dev. & $\angle\left(\mathrm{i}_{1}, a\right)$ & $\angle\left(\mathrm{i}_{1}, b\right)$ & $\angle\left(\mathrm{i}_{1}, c\right)$ & $\angle\left(\mathrm{i}_{2}, a\right)$ & $\angle\left(\mathrm{i}_{2}, b\right)$ & $\angle\left(\mathrm{i}_{2}, c\right)$ & $V_{3,1} / \mathrm{cm}^{-1}$ & $V_{3,2} / \mathrm{cm}^{-1}$ \\
\hline $\mathrm{HF} / 6-31 \mathrm{G}(\mathrm{d}, \mathrm{p})$ & 9.766 & -220 & 3.599 & -2 & 2.762 & -16 & 27.71 & 117.71 & 90.00 & 149.42 & 59.42 & 89.99 & 191.4 & 938.0 \\
\hline $\mathrm{HF} / 6-31+\mathrm{G}(\mathrm{d}, \mathrm{p})$ & 9.744 & -199 & 3.591 & 6 & 2.757 & -11 & 28.01 & 117.98 & 88.90 & 149.56 & 59.66 & 87.76 & 155.5 & 943.2 \\
\hline $\mathrm{HF} / 6-31++\mathrm{G}(\mathrm{d}, \mathrm{p})$ & 9.746 & -201 & 3.591 & 6 & 2.756 & -10 & 27.99 & 117.98 & 89.13 & 149.59 & 59.65 & 88.24 & 159.0 & 944.5 \\
\hline $\mathrm{HF} / 6-311 \mathrm{G}(\mathrm{d}, \mathrm{p})$ & 9.780 & -235 & 3.597 & 0 & 2.764 & -18 & 28.05 & 118.01 & 88.68 & 149.51 & 59.65 & 87.33 & 168.6 & 945.4 \\
\hline $\mathrm{HF} / 6-311+\mathrm{G}(\mathrm{d}, \mathrm{p})$ & 9.759 & -214 & 3.592 & 4 & 2.761 & -15 & 28.31 & 118.25 & 88.26 & 149.60 & 59.85 & 86.45 & 162.7 & 963.7 \\
\hline $\mathrm{HF} / 6-311++\mathrm{G}(\mathrm{d}, \mathrm{p})$ & 9.765 & -219 & 3.592 & 5 & 2.760 & -14 & 28.25 & 118.21 & 88.61 & 149.65 & 59.81 & 87.17 & 165.2 & 961.4 \\
\hline $\mathrm{HF} / 6-311++\mathrm{G}(3 \mathrm{df}, 2 \mathrm{pd})$ & 9.812 & -267 & 3.604 & -7 & 2.768 & -22 & 28.10 & 118.10 & 89.99 & 149.70 & 59.70 & 89.99 & 193.1 & 967.7 \\
\hline B3LYP/6-31G(d,p) & 9.529 & 16 & 3.571 & 26 & 2.728 & 18 & 27.68 & 117.68 & 90.00 & 149.35 & 59.35 & 90.00 & 176.8 & 692.4 \\
\hline B3LYP/6-31+G(d,p) & 9.497 & 48 & 3.557 & 40 & 2.720 & 26 & 28.19 & 118.13 & 88.36 & 149.54 & 59.76 & 86.69 & 111.2 & 729.7 \\
\hline B3LYP/6-31++G(d,p) & 9.495 & 51 & 3.557 & 40 & 2.720 & 26 & 28.22 & 118.16 & 88.24 & 149.52 & 59.78 & 86.42 & 112.0 & 727.2 \\
\hline B3LYP/6-311G(d,p) & 9.564 & -19 & 3.573 & 24 & 2.733 & 13 & 28.00 & 117.97 & 88.71 & 149.42 & 59.56 & 87.35 & 144.7 & 656.9 \\
\hline B3LYP/6-311+G(d,p) & 9.533 & 12 & 3.567 & 30 & 2.730 & 16 & 28.45 & 118.36 & 87.92 & 149.54 & 59.90 & 85.77 & 112.3 & 709.7 \\
\hline B3LYP/6-311++G(d,p) & 9.535 & 10 & 3.567 & 30 & 2.730 & 16 & 28.42 & 118.34 & 88.05 & 149.56 & 59.88 & 86.03 & 114.4 & 708.2 \\
\hline B3LYP/6311++G(3df,2pd) & 9.599 & -53 & 3.583 & 14 & 2.740 & 6 & 28.16 & 118.16 & 89.66 & 149.70 & 59.71 & 89.31 & 134.7 & 699.9 \\
\hline B3LYP/cc-pVDZ & 9.518 & 27 & 3.572 & 25 & 2.729 & 17 & 27.70 & 117.70 & 89.99 & 149.43 & 59.43 & 89.98 & $\ldots$ & $\ldots$ \\
\hline B3LYP/cc-pVTZ & 9.598 & -53 & 3.585 & 12 & 2.741 & 5 & 28.04 & 118.04 & 89.95 & 149.63 & 59.63 & 89.90 & $\ldots$ & $\ldots$ \\
\hline B3LYP/cc-pVQZ & 9.605 & -59 & 3.584 & 13 & 2.741 & 5 & 28.16 & 118.15 & 89.58 & 149.69 & 59.71 & 89.14 & $\ldots$ & $\ldots$ \\
\hline MP2/6-31G(d,p) & 9.498 & 47 & 3.621 & -24 & 2.754 & -8 & 27.45 & 117.45 & 90.00 & 149.02 & 59.02 & 89.99 & 207.6 & 849.6 \\
\hline MP2/6-31+G(d,p) & 9.438 & 107 & 3.610 & -13 & 2.748 & -3 & 28.13 & 118.00 & 87.58 & 149.04 & 59.51 & 85.12 & 135.9 & 875.6 \\
\hline $\mathrm{MP} 2 / 6-31++\mathrm{G}(\mathrm{d}, \mathrm{p})$ & 9.438 & 108 & 3.609 & -13 & 2.748 & -2 & 28.15 & 118.03 & 87.65 & 149.07 & 59.52 & 85.22 & 139.9 & 879.6 \\
\hline MP2/6-311G(d,p) & 9.467 & 78 & 3.610 & -13 & 2.752 & -6 & 28.17 & 118.03 & 87.49 & 148.92 & 59.44 & 84.90 & 151.6 & 861.2 \\
\hline $\mathrm{MP} 2 / 6-311+\mathrm{G}(\mathrm{d}, \mathrm{p})$ & 9.440 & 105 & 3.605 & -8 & 2.749 & -3 & 28.46 & 118.29 & 87.14 & 149.02 & 59.69 & 84.17 & 136.4 & 902.2 \\
\hline MP2/6-311++G(d,p) & 9.443 & 102 & 3.605 & -8 & 2.748 & -2 & 28.42 & 118.27 & 87.29 & 149.05 & 59.66 & 84.47 & 138.8 & 898.4 \\
\hline MP2/6-311++G(3df,2pd) & 9.564 & -19 & 3.635 & -38 & 2.767 & -21 & 27.78 & 117.78 & 89.75 & 149.26 & 59.26 & 89.50 & 153.7 & 845.7 \\
\hline MP2/cc-pVDZ & 9.428 & 117 & 3.594 & 2 & 2.736 & 10 & 27.59 & 117.59 & 89.99 & 149.11 & 59.11 & 89.98 & $\ldots$ & $\ldots$ \\
\hline $\mathrm{MP} 2 / \mathrm{cc}-\mathrm{pVTZ}$ & 9.548 & -3 & 3.640 & -43 & 2.769 & -23 & 27.79 & 117.77 & 89.11 & 149.18 & 59.24 & 88.21 & $\ldots$ & $\ldots$ \\
\hline MP2/cc-pVQZ & 9.587 & -42 & 3.648 & -51 & 2.776 & -30 & 27.77 & 117.76 & 89.43 & 149.24 & 59.26 & 88.86 & $\ldots$ & $\ldots$ \\
\hline $\mathrm{CCSD} / 6-311++\mathrm{G}(\mathrm{d}, \mathrm{p})$ & 9.482 & 64 & 3.581 & 16 & 2.736 & 10 & 28.37 & 118.26 & 87.64 & 149.20 & 59.66 & 85.18 & $\ldots$ & $\ldots$ \\
\hline $\mathrm{CCSD} / \mathrm{cc}-\mathrm{pVDZ}$ & 9.453 & 92 & 3.570 & 27 & 2.724 & 21 & 27.66 & 117.66 & 89.99 & 149.19 & 59.19 & 89.99 & 237.9 & 876.3 \\
\hline $\mathrm{CCSD} / \mathrm{cc}-\mathrm{pVTZ}$ & 9.591 & -45 & 3.617 & -20 & 2.760 & -14 & 27.88 & 117.88 & 89.50 & 149.33 & 59.35 & 88.99 & $\ldots$ & $\ldots$ \\
\hline Experiment ${ }^{\mathrm{a}}$ & 9.545 & & 3.597 & & 2.746 & & 26.34 & 116.34 & 89.91 & 147.59 & 58.13 & 84.69 & 183.2 & 764.8 \\
\hline
\end{tabular}

${ }^{a}$ With respect to the XIAM fit.

of enantiomers as shown in Fig. 2. This symmetry breaking is frequently observed in cases where an ethyl group is attached directly to a carbonyl group. It induced us to study the torsional behavior of the ethyl group in more detail by calculating a two-dimensional potential energy surface (PES) as a function of the torsional angles $\varphi_{1}=\angle\left(\mathrm{O}_{2}, \mathrm{C}_{1}, \mathrm{C}_{7}, \mathrm{C}_{8}\right)$ and $\varphi_{2}$ $=\angle\left(\mathrm{O}_{2}, \mathrm{C}_{1}, \mathrm{C}_{3}, \mathrm{H}_{4}\right)$ at the MP2/6-311++G(d,p) and B3LYP/6$311++\mathrm{G}(\mathrm{d}, \mathrm{p})$ levels of theory. We optimized the geometry with $\varphi_{1}$ and $\varphi_{2}$ fixed at certain values in a grid of $10^{\circ}$. Due to symmetry, calculations for only one sixth of the total PES are needed. The corresponding energies were parameterized with a two-dimensional Fourier expansion based on terms, representing the correct symmetry of the angles $\varphi_{1}$ and $\varphi_{2}$. The corresponding coefficients are reported in Table S-4 in the supplementary material. ${ }^{14}$ The B3LYP-PES is smoother and less Fourier coefficients were needed than in the case of the MP2 method for a parameterization with the same quality (see Table S-4 in the supplementary material). ${ }^{14} \mathrm{Fi}$ nally, using these Fourier coefficients the energy surface was drawn as a contour plot given in Figs. 3 and 4. In both cases,

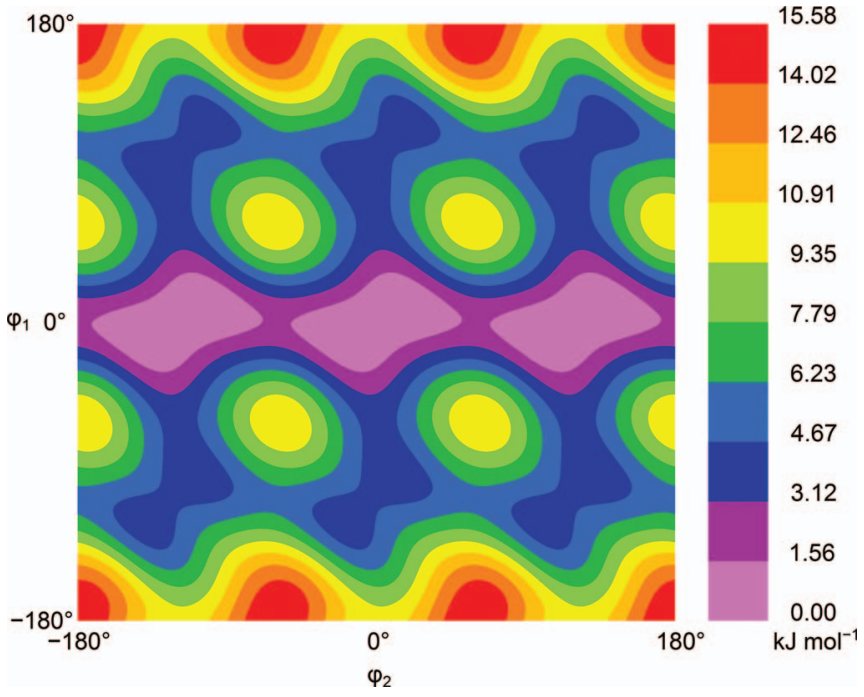

FIG. 3. The potential surface of ethyl methyl ketone obtained by rotating the ethyl group and the acetyl methyl group calculated at the MP2/ 6-311++G(d,p) level of theory. 


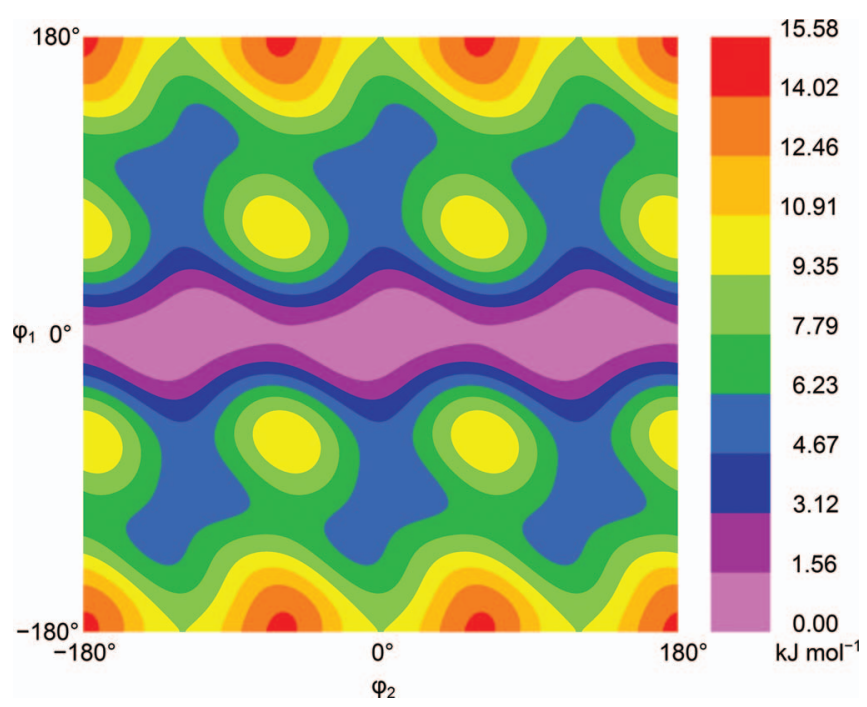

FIG. 4. The potential surface of ethyl methyl ketone obtained by rotating the ethyl group and the acetyl methyl group calculated at the B3LYP/ $6-311++G(d, p)$ level of theory.

extremely broad minima exist in the region centered at $\varphi_{1}$ $=0^{\circ}, \varphi_{2}=0^{\circ}$ and $\pm 120^{\circ}$. The broad minima are more pronounced in the PES calculated at the B3LYP/6-311++G(d,p) level of theory. A closer look at each of these broad minima shows a clearly double minimum with a maximum between them (see Fig. S-F2 and S-F3 in the supplementary material). ${ }^{14}$ To study this in detail, a further one-dimensional energy plot was carried out, where we rotated the methyl group by varying the angle $\varphi_{2}$ in steps of $1^{\circ}$ while optimizing all other geometry parameters. Also here, it can be recognized that the potential curve calculated at the HF/6-311++G(d,p) level is very flat in the range from $\varphi_{2}=-20^{\circ}$ to $+20^{\circ}$ (as well as $-130^{\circ}$ to $-110^{\circ}$ and $110^{\circ}$ to $130^{\circ}$ ) (Fig. 5). Calculations at the MP2 and B3LYP methods and the same basis set show clearly two minima at $\varphi_{2} \approx \pm 10^{\circ}$ (as well as

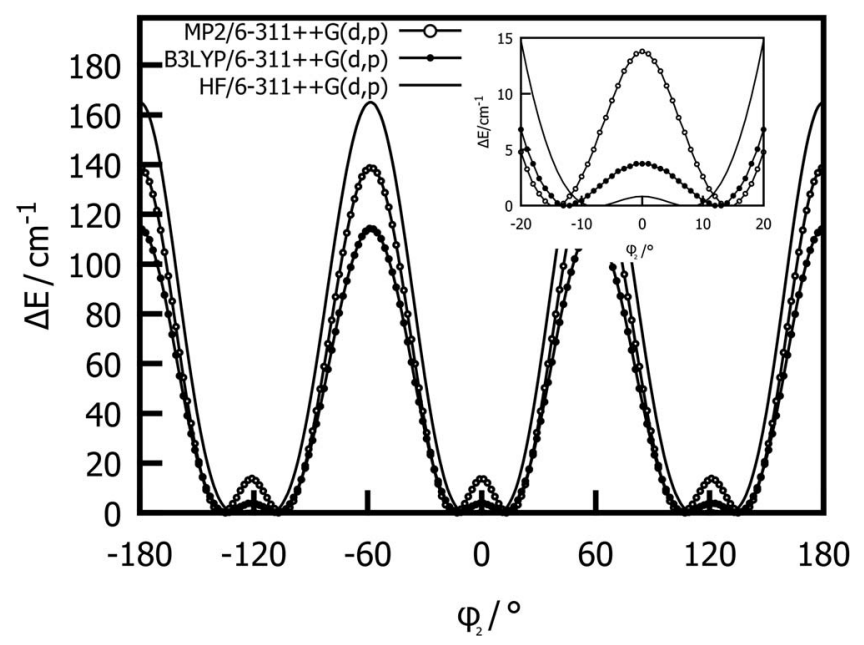

FIG. 5. Potential energy curve obtained by rotating the acetyl methyl group around the $\mathrm{C}_{1}-\mathrm{C}_{3}$ bond (for atom number see Fig. 1) by varying the dihedral angle $\varphi_{2}=\angle\left(\mathrm{O}_{2}, \mathrm{C}_{1}, \mathrm{C}_{3}, \mathrm{H}_{4}\right)$ with a step width of $1^{\circ}$ calculated using the same methods and basis set given in the caption of Fig. 2. The relative energies with respect to the lowest energy conformer are given. The double minimum located between $\varphi_{2}=-20^{\circ}$ and $+20^{\circ}$ is emphasized in an enlarged scale.

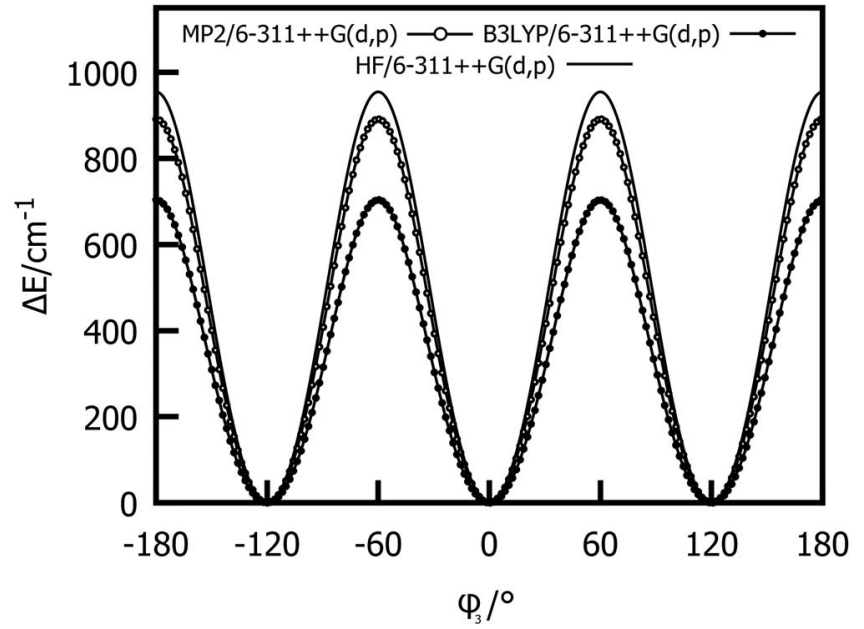

FIG. 6. The potential energy curve obtained by rotating the ethyl methyl group around the $\mathrm{C}_{7}-\mathrm{C}_{8}$ bond (for atom number see Fig. 1) by varying the dihedral angle $\varphi_{3}=\angle\left(\mathrm{C}_{1}, \mathrm{C}_{7}, \mathrm{C}_{8}, \mathrm{H}_{9}\right)$ with a step width of $1^{\circ}$ calculated using the same methods and basis set given in the caption of Fig. 2. The relative energies with respect to the lowest energy conformer are given.

$-130^{\circ} /-110^{\circ}$ and $110^{\circ} / 130^{\circ}$ ) which corresponds to the fully optimized structures. For a comparison, no double minimum occurred when we rotated the ethyl methyl group by fixing and varying the dihedral angle $\varphi_{3}=\angle\left(\mathrm{C}_{1}, \mathrm{C}_{7}, \mathrm{C}_{8}, \mathrm{H}_{9}\right)$ in a grid of $1^{\circ}$ while all other parameters were optimized (see the energy potential curve in Fig. 6). There, a normal $V_{3}$ potential has been found without a pronounced $\mathrm{V}_{6}$ contribution. These data were parameterized by Fourier series, which are also given in Table S-3 in the supplementary material (S-3b and $\mathrm{S}-3 \mathrm{c}){ }^{14}$

From Figs. 5 and 6, the calculated barriers to internal rotations of both, the acetyl methyl and the ethyl methyl group, at the MP2/6-311++G(d,p) level of theory can be determined to be $139 \mathrm{~cm}^{-1}$ and $898 \mathrm{~cm}^{-1}$, respectively. These values differ strongly by using the same basis set but other methods. Using the B3LYP method, $114 \mathrm{~cm}^{-1}$ and $708 \mathrm{~cm}^{-1}$ have been found and for the HF methods, the values are $165 \mathrm{~cm}^{-1}$ and $961 \mathrm{~cm}^{-1}$. The barriers were also calculated using various combinations of methods and basis sets, as given in Table I. They differ also in cases, where the same method but different basis sets have been used.

\section{SPECTRAL ANALYSIS}

\section{A. Microwave spectrum}

As mentioned in the Introduction, there are two methyl groups in ethyl methyl ketone which can undergo internal rotation. The torsion of the acetyl methyl group has a low barrier of approximately $181 \mathrm{~cm}^{-1}$ and causes a wide splitting of each line in the spectrum in an A and E component. ${ }^{1}$

At the beginning, the rotational constants given in Ref. 1 were used to predict the rotational transitions in the frequency range from 2 to $40 \mathrm{GHz}$ for the A species. Many $b$-type transitions were immediately found. All of them are very strong. The dipole moments in $a$-, $b$-, and $c$-direction were measured to be $0.079(25) \mathrm{D}, 2.775(15) \mathrm{D}$, and $0.0 \mathrm{D}$, respectively, as reported in Ref. 1 . This was confirmed by the values obtained 


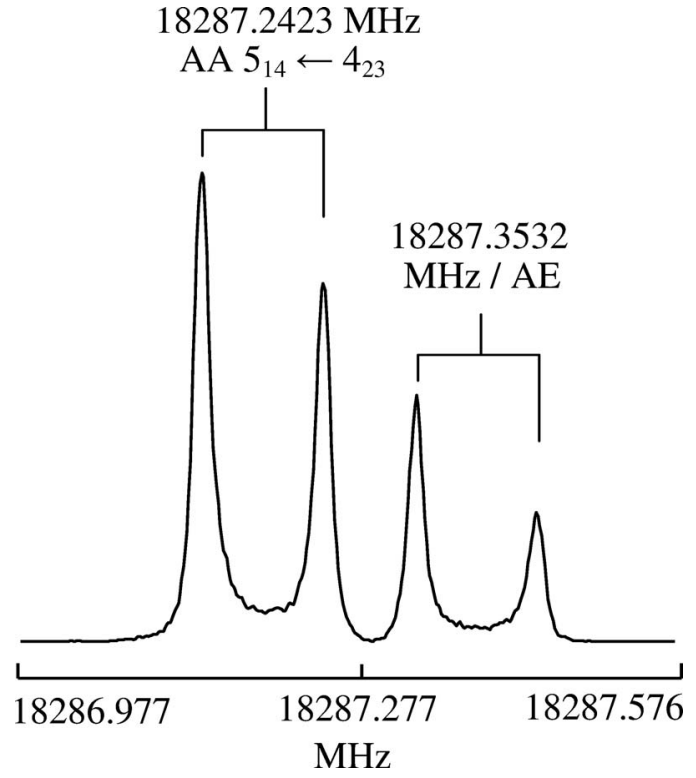

FIG. 7. A spectrum showing the AA and AE species of the $5_{14} \leftarrow 4_{23}$ transition of ethyl methyl ketone. The experimental resolution was $4 \mathrm{kHz}$, the typical line width approximately $30 \mathrm{kHz}(\mathrm{FWHH})$. The splitting indicated by brackets is due to the Doppler effect. For this spectrum 53 FIDs (free induction decays) were co-added.

by quantum chemical calculations, which are $0.14 \mathrm{D}, 3.36 \mathrm{D}$, and $0.02 \mathrm{D}$, respectively, using the MP2/6-311++G(d,p) level of theory. No $c$-type transitions are expected. The dipole moment in the $a$-direction is very small, however not zero. Therefore, some $a$-type transitions could also be measured.

In a next step, a prediction including the internal rotation of the acetyl methyl group has been carried out using the program XIAM. The starting value for the internal rotation barrier of $181 \mathrm{~cm}^{-1}$ was taken from Ref. 1 . The angles between the internal rotor axis and the principal axes of inertia were taken from the optimized geometry carried out at the MP2/6-311++G(d,p) level of theory.

The E species of some $a$ - and $b$-type transitions which have small A-E splittings of a few ten $\mathrm{MHz}$ could be found easily. Transitions with large A-E splittings were more difficult to find. Often, small scans of 5-10 MHz were needed. With these E species lines, the barrier as well as the angles between the internal rotor axis and the principal axes could be fitted. Using the fitted parameters, a new prediction was carried out and all E species lines could be measured directly.

All A species lines appear as doublets, which can be seen in a spectrum recorded in the high resolution mode of the spectrometers shown in Fig. 7. Some E species lines are clearly triplets (see Fig. 8). Some others have larger splittings and the triplet components are separated by up to $1.5 \mathrm{MHz}$. As discussed already in Refs. 5 and 6, the A species additionally split into two torsional components due to the internal rotation of the ethyl methyl groups, which we will refer as the $\mathrm{AA}$ and $\mathrm{AE}$ species, and the $\mathrm{E}$ species into three components, which will be called the EA, EE, and EE* species. The first letter of the symmetry label refers to the acetyl methyl group and the second letter to the ethyl methyl group.

In a next step, the XIAM code was used to calculate the complete spectrum with all five torsional components. A start

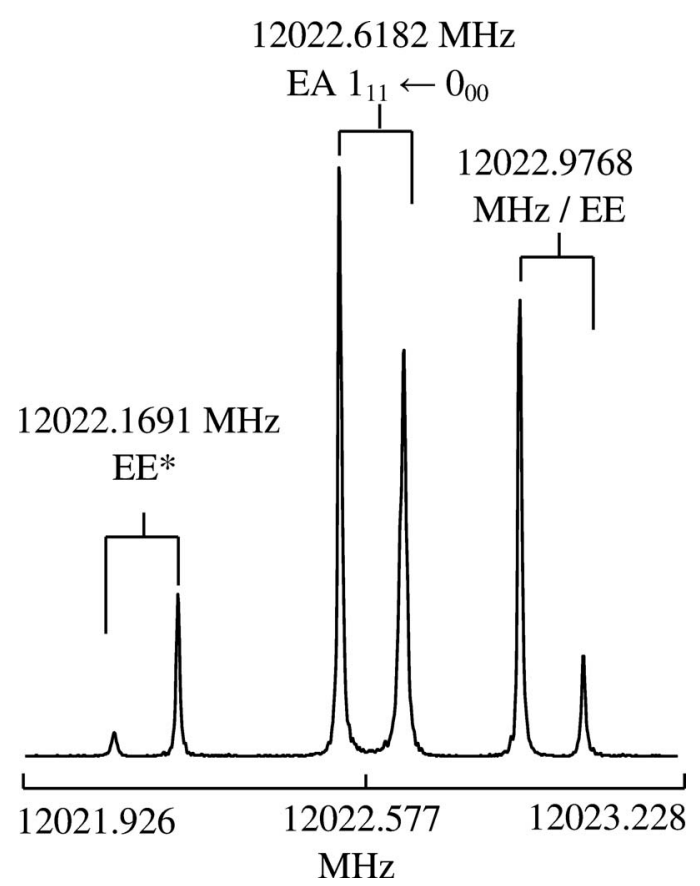

FIG. 8. A spectrum showing the EA, EE, and EE* species of the $1_{11} \leftarrow 0_{00}$ transition. For this spectrum 28 FIDs were co-added.

value of $795 \mathrm{~cm}^{-1}$ was taken as the barrier to internal rotation of the ethyl methyl group, as given in Ref. 2. The angles between the internal rotor axis and the principal axes were taken from quantum chemical calculations. The predicted absolute frequencies were often off by up to $1 \mathrm{MHz}$, but the splittings, mainly in the order of a few hundred $\mathrm{kHz}$, could be calculated with high accuracy. From the order of the AA and AE as well as the EA, EE, and $\mathrm{EE}^{*}$ species, we could easily assign the fine splittings in each spectrum.

\section{B. Fits}

First, the data set which contains totally 295 rotational transitions was fitted using the program XIAM. XIAM has been described in details in Ref. 9. It uses a combined axis method (CAM) which sets up the rotation-torsion Hamiltonian in the rho-axis system (RAM) for each top, then converts the RAM parameters into principal axis system (PAM) parameters. Using XIAM, standard parameters like the rotational constants $A, B$, and $C$, the centrifugal distortion constants, and the two barriers to internal rotation $V_{3,1}$ and $V_{3,2}$ for each methyl group could be determined with high accuracy. It should be noted that $J$ and $K$ values are limited to 9 and 4 , respectively, due to the very low rotational temperature (about $1 \mathrm{~K}$ ) in the molecular beam. The angles $\angle\left(\mathrm{i}_{1}, i\right)$ and $\angle\left(\mathrm{i}_{2}, i\right)(i=a, b, c)$ between the internal rotor axis and the $a, b$, and $c$ principal axes, as well as three higher order parameters $\mathrm{D}_{\mathrm{pi} 2 J}, \mathrm{D}_{\mathrm{pi} 2 K}$, and $\mathrm{D}_{\mathrm{pi} 2-}$ could also be determined. All fitted parameters are given in Table II. The standard deviation obtained from the program XIAM was $18.2 \mathrm{kHz}$, much larger than our experimental accuracy. This will be discussed in Sec. V.

Then, the same set of rotational transitions was fitted using the BELGI-Cs-2Tops code. This program code has been 
TABLE II. The molecular parameters referred to the PAM system obtained from a fit using the programs XIAM and BELGI-Cs-2Tops.

\begin{tabular}{|c|c|c|c|c|}
\hline Constant & Unit & XIAM & BELGI-Cs-2Tops ${ }^{\mathrm{a}}$ & Calc. ${ }^{b}$ \\
\hline$A$ & $\mathrm{GHz}$ & $9.5453136(18)$ & $9.5021(52)$ & 9.443 \\
\hline$B$ & $\mathrm{GHz}$ & $3.5972498(12)$ & $3.59892(88)$ & 3.605 \\
\hline C & $\mathrm{GHz}$ & $2.7463872(12)$ & $2.7470076(38)$ & 2.748 \\
\hline$\Delta_{\mathrm{J}}$ & $\mathrm{kHz}$ & $0.6466(45)$ & $0.6637(14)$ & \\
\hline$\Delta_{\mathrm{JK}}$ & $\mathrm{kHz}$ & $2.461(21)$ & & \\
\hline$\Delta_{\mathrm{K}}$ & $\mathrm{kHz}$ & $7.789(84)$ & & \\
\hline$\delta_{\mathrm{J}}$ & $\mathrm{kHz}$ & $0.1509(21)$ & & \\
\hline$\delta_{\mathrm{K}}$ & $\mathrm{kHz}$ & $0.531(35)$ & & \\
\hline$V_{3,1}$ & $\mathrm{~cm}^{-1}$ & $183.1702(89)$ & 181.502(98) & 138.8 \\
\hline$I_{\alpha, 1}$ & $\mathrm{u} \AA^{2}$ & 3.1986 (fixed) $^{\mathrm{c}}$ & $3.157(17)$ & 3.1943 \\
\hline$\angle\left(\mathrm{i}_{1}, a\right)$ & $\circ$ & $26.3375(42)$ & $26.24(12)$ & 28.42 \\
\hline$\angle\left(\mathrm{i}_{1}, b\right)$ & $\circ$ & $116.3373(44)$ & $116.24(12)$ & 118.27 \\
\hline$\angle\left(\mathrm{i}_{1}, c\right)$ & $\circ$ & 89.91(11) & 90.0 (fixed) & 87.29 \\
\hline $\mathrm{D}_{\mathrm{pi} 2 J, 1}$ & $\mathrm{kHz}$ & $151.5(13)$ & & \\
\hline $\mathrm{D}_{\mathrm{pi} 2 K, 1}$ & $\mathrm{MHz}$ & $-1.6908(62)$ & & \\
\hline $\mathrm{D}_{\mathrm{pi} 2-, 1}$ & $\mathrm{kHz}$ & $79.51(75)$ & & \\
\hline$V_{3,2}$ & $\mathrm{~cm}^{-1}$ & $764.8(16)$ & $763.87(65)$ & 898.4 \\
\hline$I_{\alpha, 2}$ & $\mathrm{u} \AA^{2}$ & $3.1986\left(\right.$ fixed) ${ }^{c}$ & $3.131(18)$ & 3.1610 \\
\hline$\angle\left(\mathrm{i}_{2}, a\right)$ & $\circ$ & $147.59(82)$ & $150.04(40)$ & 149.05 \\
\hline$\angle\left(\mathrm{i}_{2}, b\right)$ & $\circ$ & $58.13(80)$ & $60.04(40)$ & 59.66 \\
\hline$\angle\left(\mathrm{i}_{2}, c\right)$ & $\circ$ & $84.69(12)$ & 90.0 (fixed) & 84.47 \\
\hline$F_{12}$ & $\mathrm{~cm}^{-1}$ & not fitted & $0.651(41)$ & \\
\hline$\sigma / \mathrm{N}^{\mathrm{d}}$ & $\mathrm{kHz}$ & $18.2 / 295$ & $5.3 / 295$ & \\
\hline$\sigma_{\mathrm{A}} / \mathrm{N}_{\mathrm{A}}^{\mathrm{e}}$ & $\mathrm{kHz}$ & & $6.0 / 64$ & \\
\hline$\sigma_{\mathrm{E} 1} / \mathrm{N}_{\mathrm{E} 1}$ & $\mathrm{kHz}$ & & $4.6 / 58$ & \\
\hline$\sigma_{\mathrm{E} 2} / \mathrm{N}_{\mathrm{E} 2}$ & $\mathrm{kHz}$ & & $6.2 / 63$ & \\
\hline$\sigma_{\mathrm{E} 3} / \mathrm{N}_{\mathrm{E} 3}$ & $\mathrm{kHz}$ & & $4.4 / 53$ & \\
\hline$\sigma_{\mathrm{E} 4} / \mathrm{N}_{\mathrm{E} 4}$ & kHz & & $4.6 / 57$ & \\
\hline
\end{tabular}

${ }^{a}$ BELGI-Cs-2Tops constants are transformed into PAM constants using Eqs. 10-14 of Ref. 21.

${ }^{\mathrm{b}}$ Calculation at the MP2/6-311++G(d,p) level of theory using the program Gaussian 09 .

${ }^{\mathrm{c}}$ Derived from $\mathrm{F}_{0}=158 \mathrm{GHz}$ (fixed).

${ }^{\mathrm{d}}$ Standard deviation of the fit/total number of lines.

${ }^{\mathrm{e} S}$ Standard deviation/number of lines of each symmetry species.

developed to fit the high-resolution torsion-rotational spectra of molecules with two inequivalent methyl rotors and a $\mathrm{C}_{\mathrm{S}}$ symmetry at equilibrium. Using this code, the rotational spectra of methyl acetate, methyl propionate, and DMBA isomers could be reproduced within their experimental accuracy. BELGI-Cs-2Tops has been described in details in Refs. 5 and 10 and will not be repeated here. The readers are also referred to Ref. 21 for the theoretical model on which the code is initially based. All measured lines of ethyl methyl ketone were weighted in the least squares fit by the inverse of the square of the estimated measurement error of $4 \mathrm{kHz}$. In total, the same data set containing 295 rotational transitions in the ground torsional state were fitted using 19 molecular parameters to a unitless standard deviation of 1.36 (i.e., $5.3 \mathrm{kHz}$ ). All parameters are given in Table III. Parameters, which can be transformed into the PAM system and compared with the parameters from XIAM, are also given in Table II. A list of all frequencies fitted using both program codes along with the residuals are available in Table S-5 in the supplementary material. ${ }^{14}$

It should be noted that in all calculations using BELGICs-2Tops the symmetry labels are based on the permutation-
TABLE III. Spectroscopic constants of ethyl methyl ketone obtained with the program BELGI-Cs-2Tops.

\begin{tabular}{|c|c|c|}
\hline Operator $^{\mathrm{a}}$ & Parameter $^{\mathrm{b}}$ & Value $/ \mathrm{cm}^{-1}$ \\
\hline$J_{\mathrm{z}}{ }^{2}$ & $A$ & $0.349221(66)$ \\
\hline$J_{\mathrm{x}}{ }^{2}$ & $B$ & $0.121177(20)$ \\
\hline$J_{\mathrm{y}}{ }^{2}$ & $C$ & $0.09163031(13)$ \\
\hline$-J^{4}$ & $\Delta_{J}$ & $0.22138(46) \times 10^{-7}$ \\
\hline$-J^{2} J_{\mathrm{z}}^{2}$ & $\Delta_{J K}$ & $0.1187(19) \times 10^{-6}$ \\
\hline$-J_{\mathrm{z}}^{4}$ & $\Delta_{K}$ & $-0.78(53) \times 10^{-6}$ \\
\hline$-2 J^{2}\left(J_{\mathrm{x}}^{2}-J_{\mathrm{y}}^{2}\right)$ & $\delta_{J}$ & $0.5233(20) \times 10^{-8}$ \\
\hline$-J_{\mathrm{z}}^{2}\left(J_{\mathrm{x}}^{2}-J_{\mathrm{y}}^{2}\right)$ & $\delta_{K}$ & $0.5478(42) \times 10^{-7}$ \\
\hline$p_{1}^{2}$ & $F_{1}$ & $5.5831^{\mathrm{d}}$ \\
\hline$p_{2}^{2}$ & $F_{2}$ & $5.5664^{\mathrm{d}}$ \\
\hline$p_{1} p_{2}$ & $F_{12}$ & $0.651(41)$ \\
\hline$(1 / 2)\left(1-\cos 3 \alpha_{1}\right)$ & $V_{3,1}$ & $181.502(98)$ \\
\hline$(1 / 2)\left(1-\cos 3 \alpha_{1}\right) J^{2}$ & $V_{3, I J}$ & $-0.0001463(31)$ \\
\hline$(1 / 2)\left(1-\cos 3 \alpha_{1}\right) J_{\mathrm{z}}{ }^{2}$ & $V_{3,1 K}$ & $0.00555(15)$ \\
\hline$\left(\mathrm{J}_{\mathrm{x}}^{2}-\mathrm{J}_{\mathrm{y}}^{2}\right)\left(1-\cos 3 \alpha_{1}\right)$ & $V_{3, I B C}$ & $-0.619(29) \times 10^{-4}$ \\
\hline$(1 / 2)\left(1-\cos 3 \alpha_{2}\right)$ & $V_{3,2}$ & $763.87(65)$ \\
\hline$J_{\mathrm{z}} p_{1}$ & $q_{1}$ & $-0.6309(21)$ \\
\hline$J_{\mathrm{z}} J^{2} p_{1}$ & $q_{1 J}$ & $0.963(42) \times 10^{-6}$ \\
\hline$J_{\mathrm{z}} J_{\mathrm{z}}^{2} p_{1}$ & $q_{1 K}$ & $-0.1794(99) \times 10^{-4}$ \\
\hline$J_{\mathrm{z}} p_{2}$ & $q_{2}$ & $-0.6060^{\mathrm{e}}$ \\
\hline$J_{\mathrm{x}} p_{1}$ & $r_{1}$ & $-0.10037(41)$ \\
\hline$J_{\mathrm{x}} p_{2}$ & $r_{2}$ & $-0.1133(18)$ \\
\hline \multicolumn{3}{|c|}{ 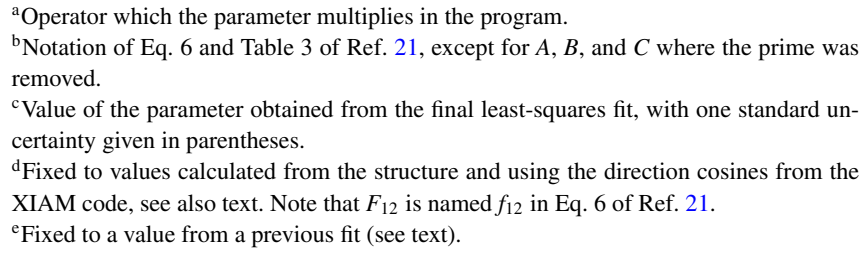 } \\
\hline
\end{tabular}

inversion group $\mathrm{G}_{18} .{ }^{22}$ The local mode symmetry labels correspond to the $\mathrm{G}_{18}$ symmetry labels by AA $\leftrightarrow \mathrm{A} 1 / \mathrm{A} 2, \mathrm{AE} \leftrightarrow$ $\mathrm{E} 2, \mathrm{EA} \leftrightarrow \mathrm{E} 1, \mathrm{EE} \leftrightarrow \mathrm{E} 3$, and $\mathrm{EE}^{*} \leftrightarrow \mathrm{E} 4$.

\section{RESULTS AND DISCUSSION}

Using the program XIAM, 295 torsional components of ethyl methyl ketone could be fitted by floating the rotational constants $A, B, C$, the centrifugal distortion constants $\Delta_{J}, \Delta_{J K}$, $\Delta_{K}, \delta_{J}, \delta_{K}$, the two barrier heights $V_{3,1}$ and $V_{3,2}$ for each top, the polar-coordinates of the internal rotation axes in the principal axes system $(\delta$ and $\varepsilon$ ), and three higher order parameters $\mathrm{D}_{\mathrm{pi} 2 J}, \mathrm{D}_{\mathrm{pi} 2 K}$, and $\mathrm{D}_{\mathrm{pi} 2--}$. The angles between the two methyl rotors and the principal axes $\angle\left(\mathrm{i}_{1}, i\right)$ and $\angle\left(\mathrm{i}_{2}, i\right)(i=a, b, c)$ were derived from $\delta$ and $\varepsilon$. The moment of inertia of the two tops $I_{\alpha, 1}$ and $I_{\alpha, 2}$ were kept fixed at $3.1986 \mathrm{u}^{2}$, corresponding to $F_{0}=158 \mathrm{GHz}$, a value often found for methyl groups, since only transitions in the rotational ground state were measured and these parameters are thus strongly correlated with $V_{3,1}$ and $V_{3,2}$. With this set of 16 parameters, the spectrum could be reproduced with a root-mean-square (rms) deviation of $18.2 \mathrm{kHz}$, much higher than our experimental accuracy. We found some transitions where the frequencies of the EA (E1), EE (E3), and EE* (E4) species, or in some cases even all five torsional species, are systematically off by almost the same value. It is clear that this systematical error was caused by 
some missing parameters which are not available in the XIAM code.

The BELGI-Cs-2Tops code floats 19 parameters, which are the rotational constants $A, B, C$, the five centrifugal distortion constants $D_{J}, D_{J K}, D_{K}, \delta_{J}, \delta_{K}$, the two barrier heights $V_{31}$ (the lower barrier height of the acetyl methyl group) and $V_{32}$ (the higher barrier of the ethyl methyl group), one $J(J+1)$ and one $K^{2}$ dependent parameter $\left(V_{31 J}\right.$ and $V_{31 K}$, respectively). A $\left(J_{\mathrm{x}}{ }^{2}-J_{\mathrm{y}}{ }^{2}\right)\left(1-\cos 3 \alpha_{1}\right)$ term $\left(V_{31 B C}\right)$, as well as the rotation-torsion coupling term $q_{1}$, which multiplies the operator $J_{\mathrm{z}} p_{1}$ (equivalent to the term $-2 F_{1} \rho_{1 a}$ for top 1 term in the RAM approach) and $r_{1}$, which multiplies the operator $J_{\mathrm{x}}$ $p_{1}$ (equivalent to the term $\left.-2 F_{1} \rho_{1 b}\right)$. The $J(J+1)$ and $K^{2}$ dependences of $q_{1}$ were additionally floated. For top 2 which corresponds to the higher barrier, only the $r_{2}$ term has been fitted, while the $q_{2}$ term was kept fixed. At the beginning, $q_{2}$ has also been floated but even though the standard deviation decreased to $4.5 \mathrm{kHz}$ (slightly lower than when we fixed this parameter), larger uncertainties in the $A$ and $B$ rotational constant were found, likely due to the difficulty of un-correlating all the internal rotation and global rotation parameters while small energy splittings are present. Therefore, we decided to fix the value of the $q_{2}$ parameter to the value obtained while floating it. Finally, internal rotation constants for top $1\left(F_{1}\right)$ and for top $2\left(F_{2}\right)$ were kept fixed to the values derived from the XIAM code. One kinetic interaction term between the two tops $\left(F_{12}\right)$ could also be determined.

A number of additional higher order parameters have been used in comparison with XIAM, but the BELGI-Cs2Tops fit provides a much better quality with an rms deviation of only $5.3 \mathrm{kHz}$, almost within our measurement error.

However, the rotational constant $A$ (and $B$ to some extend) as well as the angles between the ethyl methyl internal rotor axis and the PAM $a$-axis $\angle\left(\mathrm{i}_{2}, a\right)$ or $b$-axis $\angle\left(\mathrm{i}_{2}, b\right)$ are not well determined in the BELGI-Cs-2Tops fit. This is similar to the case of syn-2,5 dimethyl-benzaldehyde, ${ }^{11}$ an isomer of DMBA which also has one low and one high barrier to internal rotation. The internal rotation parameters related to the high barrier are not so well determined, since the internal rotation splittings used for their determination are small. The ethyl methyl rotor angles also differ by a few degrees from the angles determined by the XIAM code. It should be noted that in the XIAM fit, this methyl top is slightly out of plane, whereas in the BELGI-Cs-2Tops fit, we assumed that all heavy atoms are located on a molecular plane.

The rotational constants obtained with both programs are in reasonable agreement, however, they do not agree within the standard errors. The comparison with the values from quantum chemical calculations showed that the B3LYP/6-311 method in combination with the polarization function $(\mathrm{d}, \mathrm{p})$ yielded the most accurate rotational constants with the deviations of $-18.73 \mathrm{MHz}, 24.65 \mathrm{MHz}$, and 13.20 MHz for the $A, B$, and $C$ rotational constants, respectively. A better agreement cannot be expected since the quantum chemical data refer to the equilibrium structure whereas the experimental data yield rotational constants for the ground vibrational state and no corrections have been made. At the MP2/cc-pVTZ level of theory, the best value for the $A$ rotational constant was obtained with an excellent deviation of only $3 \mathrm{MHz}$.
This is in good agreement with the calculations carried out for linalool, ${ }^{23}$ a much larger molecule than ethyl methyl ketone. The CCSD method also yielded reasonable values for the rotational constants. However, they are not much better than the calculations using the MP2 method. Therefore, we conclude that for molecules of this size, the MP2 and B3LYP methods are sufficient for calculating the rotational constants. The largest deviations were obtained using the HF method. It should be noted that all standard deviations were given in $\mathrm{MHz}$ and not in percent.

The torsional barrier of the acetyl methyl group was fitted to $183.1702(89) \mathrm{cm}^{-1}$ and $181.502(98) \mathrm{cm}^{-1}$ by the XIAM code and the BELGI-Cs-2Tops code, respectively, in good agreement with the barrier of $181.17(35) \mathrm{cm}^{-1}$ reported in Ref. 1. The barrier of $764.8(16) \mathrm{cm}^{-1}$ for the ethyl methyl group also matches the barrier of $795(10) \mathrm{cm}^{-1}$ from Ref. 2 and is similar to the barriers of $771.93(27) \mathrm{cm}^{-1}$ observed for diethyl ketone ${ }^{7}$ and $820.46(99) \mathrm{cm}^{-1}$ observed for methyl propionate. ${ }^{5}$ Splittings arising from the ethyl methyl groups are up to $4 \mathrm{MHz}$, much smaller than those from the acetyl methyl group (up to $1.2 \mathrm{GHz}$ ). However, they are still much larger than splittings found for some other molecules with similar barriers to internal rotation (up to $500 \mathrm{kHz}$ and $600 \mathrm{kHz}$ in diethyl ketone or methyl propionate, respectively). It might be due to the different location of the ethyl methyl group in the principal axis system. Comparing the experimental barriers with those obtained by quantum chemical calculations, we found that the values calculated at the MP2/6-311++G(d,p) level of theory differ by approximately $-17.5 \%$ and $24.2 \%$. However, it is known that the barriers to internal rotations calculated with this method and basis set usually have large deviation to the experimental values. A systematic quantum chemical investigation on internal rotational barriers would be helpful for assignments of microwave spectra and is planned for the future. No combination of method and basis set is currently known, which can predict the barrier height with sufficient accuracy. Table I shows that the calculated barrier for the ethyl methyl group at the B3LYP/6$31 \mathrm{G}+(\mathrm{d}, \mathrm{p})$ level of theory has the smallest deviation to the experimental value $\left(35 \mathrm{~cm}^{-1}\right)$. However, at the same level, the calculated barrier of $111 \mathrm{~cm}^{-1}$ for the acetyl methyl group has a higher deviation of $72 \mathrm{~cm}^{-1}$. Nevertheless, the same basis set without diffuse functions lead to a reasonable agreement for both barriers $\left(72 \mathrm{~cm}^{-1}\right.$ for the ethyl methyl group and 6 $\mathrm{cm}^{-1}$ for the acetyl methyl group).

The angles between the internal ethyl methyl rotor axis and the $a b$ plane are surprisingly not zero in the XIAM fit. The ethyl methyl group is tilted out of plane by an angle of $5^{\circ}$, whereas the acetyl methyl group is in-plane (see Table II). Quantum chemical calculations predicted both methyl groups in some cases in-plane, in some other cases out-of-plane or they predicted the same effect with an out-ofplane ethyl methyl group with a tilted angle between $0^{\circ}$ and $5^{\circ}$ and an in-plane acetyl methyl group, depending strongly on the methods and basis sets. The best agreement with the experimental values was carried out at the MP2/6-311G(d,p) level of theory. The B3LYP methods in combination with the Pople basis sets ${ }^{24-26}$ and the diffuse functions also yielded reasonable agreements. It could be noted that the correlation 
consistent basis sets show better agreement for the rotational constants, while the Pople basis sets could calculate better the internal rotor angles. The HF method yielded the biggest deviations both for the rotational constants and internal rotor angles. It should be noted that all calculated values are compared with the experimental values from the XIAM fit.

The same effect occurred in all other ketones we studied before where an ethyl group is attached directly to a carbonyl group. In diethyl ketone, ${ }^{7}$ each ethyl group is calculated to be out of the molecular plane by an angle of approximately $10^{\circ}$. In methyl neopentyl ketone, ${ }^{17}$ also a titled angle of $10^{\circ}$ has been found. This is a very interesting effect, which will be continued studying in our future works on ketones.

\section{CONCLUSION}

Using two molecular beam Fourier transform microwave spectrometers the torsional fine structure with all five rotational-torsional species arising from two inequivalent methyl groups of ethyl methyl ketone, the acetyl methyl group and the ethyl methyl group, could be fully resolved and analyzed in a global fit using two codes, BELGI-Cs-2Tops and XIAM. The acetyl methyl group has a relatively low barrier to internal rotation $\left(181.502(98) \mathrm{cm}^{-1}\right.$, as determined by the BELGI-Cs-2Tops code) causes splittings up to $1.2 \mathrm{GHz}$ in the spectrum. Splittings due to the ethyl methyl group are much smaller, in the order of a few hundred $\mathrm{MHz}$ up to $4 \mathrm{MHz}$. We found that for this molecule, the program BELGI-Cs-2Tops is much more suitable to analyze the spectrum compared to the XIAM code, since some additional parameters can be added. Using BELGI-Cs-2Tops, the spectrum could be reproduced within our experimental accuracy using 19 fitted parameters for 295 lines with a ratio of 15.5 lines/parameter. For the first time, the spectroscopic work was supplemented by quantum chemical calculations for this molecule. On the other hand, quantum chemical calculations were validated by rotational spectroscopy. We found reasonable agreements between the calculated and experimental results obtained from both XIAM and BELGI-Cs-2Tops fits. With advanced quantum chemical methods, it could be shown that the equilibrium geometry of the lowest energy conformer has no mirror plane. However, in the torsional ground state an effective $\mathrm{C}_{\mathrm{s}}$ symmetry was found and BELGI-Cs-2Tops could be used with some success. A full two-dimensional potential energy surface depending on both, the torsional angle of the entire ethyl group and the acetyl methyl group, was calculated using MP2 and DFT methods. This gives a clear picture of the rather complex tunneling path of the acetyl methyl internal rotation. It also explains the rather large $\mathrm{V}_{6}$ contribution of the one-dimensional acetyl methyl potential curve.

\section{ACKNOWLEDGMENTS}

We thank the Land Nordrhein-Westfalen and the Université de Paris Est - Créteil as well as the "Start-up" project of the RWTH Aachen University for funds. Free computer time provided by the Center for Computing and Communication of the RWTH Aachen University is gratefully acknowledged. V.V. and W.S. thank the fonds of chemical industry (FCI) for a Ph.D. fellowship. We also wish to thank the HPC PROCOPE program of the DAAD for travel grants.

${ }^{1}$ L. Pierce, C. K. Chang, M. Hayashi, and R. Nelson, J. Mol. Spectrosc. 32, 449 (1969).

${ }^{2}$ N. M. Pozdeev, A. K. Mamleev, L. N. Gunderova, and R. V. Galeev, J. Struct. Chem. 29, 52 (1988).

${ }^{3}$ J. A. Kroll, S. T. Shipman, and S. L. W. Weaver, J. Mol. Spectrosc. 295, 52 (2014).

${ }^{4}$ H. V. L. Nguyen, R. Kannengiesser, and W. Stahl, Phys. Chem. Chem. Phys. 14, 11753 (2012); H. Mouhib, D. Jelisavac, L. W. Sutikdja, E. Isaak, and W. Stahl, J. Phys. Chem. A 115, 118 (2011); H. Mouhib, Y. Zhao, and W. Stahl, J. Mol. Spectrosc. 261, 59 (2010); T. Attig, L. W. Sutikdja, R. Kannengiesser, I. Kleiner, and W. Stahl, ibid. 284-285, 8 (2013); T. Attig, R. Kannengiesser, I. Kleiner, and W. Stahl, ibid. 290, 24 (2013); H. Mouhib and W. Stahl, ChemPhysChem 13, 1297 (2012).

${ }^{5}$ H. V. L. Nguyen, W. Stahl, and I. Kleiner, Mol. Phys. 110, 2035 (2012).

${ }^{6}$ D. Jelisavac, D. C. Cortés Gómez, H. V. L. Nguyen, L. W. Sutikdja, W. Stahl, and I. Kleiner, J. Mol. Spectrosc. 257, 111 (2009).

${ }^{7}$ H. V. L. Nguyen, and W. Stahl, Chem. Phys. Chem. 12, 1900 (2011).

${ }^{8}$ H. V. L. Nguyen and W. Stahl, J. Chem. Phys. 135, 024310 (2011).

${ }^{9}$ H. Hartwig and H. Dreizler, Z. Naturforsch. 51a, 923 (1996).

${ }^{10} \mathrm{M}$. Tudorie, I. Kleiner, J. T. Hougen, S. Melandri, L. W. Sutikdja, and W. Stahl, J. Mol. Spectrosc. 269, 211 (2011).

${ }^{11}$ M. Tudorie, I. Kleiner, M. Jahn, J.-U. Grabow, M. Goubet, and O. Pirali, J. Phys. Chem. A 117, 13636 (2013).

${ }^{12}$ J.-U. Grabow, W. Stahl, and H. Dreizler, Rev. Sci. Instrum. 67, 4072 (1996).

${ }^{13}$ I. Merke, W. Stahl, and H. Dreizler, Z. Naturforsch. 49a, 490 (1994).

${ }^{14}$ See supplementary material at http://dx.doi.org/10.1063/1.4878412 for detail information for quantum chemical calculations, Fourier coefficients of the potential function, and the frequency list.

${ }^{15}$ M. J. Frisch, G. W. Trucks, H. B. Schlegel et al., Gaussian 09, Revision A.02, Gaussian, Inc., Wallingford, CT, 2009.

${ }^{16}$ Y. Zhao, W. Stahl, and H. V. L. Nguyen, Chem. Phys. Lett. 545, 9 (2012).

${ }^{17}$ Y. Zhao, J. Jin, W. Stahl, and I. Kleiner, J. Mol. Spectrosc. 281, 4 (2012).

${ }^{18}$ B. Velino, L. Evangelisti, W. Caminati, and R. Fausto, J. Mol. Struct. 976, 136 (2010).

${ }^{19}$ M. J. Tubergen, A. R. Conrad, R. E. Chavez, III, I. Hwang, R. D. Suenram, J. J. Pajski, and B. H. Pate, J. Mol. Spectrosc. 251, 330 (2008).

${ }^{20}$ C. Cabezas, I. Peña, A. M. Daly, and J. L. Alonso, Chem. Commun. 49, 10826 (2013).

${ }^{21}$ N. Ohashi, J. T. Hougen, R. D. Suenram, F. J. Lovas, Y. Kawashima, M. Fujitake, and J. Pyka, J. Mol. Spectrosc. 227, 28 (2004).

${ }^{22}$ H. Dreizler, Z. Naturforsch. 16a, 1354 (1961).

${ }^{23}$ H. V. L. Nguyen, H. Mouhib, S. Klahm, W. Stahl, and I. Kleiner, Phys. Chem. Chem. Phys. 15, 10012 (2013).

${ }^{24}$ R. Ditchfield, W. J. Hehre, and J. A. Pople, J. Chem. Phys. 54, 724 (1971).

${ }^{25}$ A. D. McLean and G. S. Chandler, J. Chem. Phys. 72, 5639 (1980).

${ }^{26}$ G. A. Petersson, A. Bennett, T. G. Tensfeldt, M. A. Al-Laham, W. A. Shirley, and J. Mantzaris, J. Chem. Phys. 89, 2193 (1988). 